\title{
Comparison of Radar Derived Rain Attenuation with the RazakSAT's X-Band Link Signal Measurement
}

\author{
K. Badron, A. F. Ismail, A. Z. Jusoh, N. H. M. Sobli, M. Ismail, and W. Hashim
}

\begin{abstract}
The preliminary analysis involving comparison between radar derived attenuation using an S-band meteorological radar and measured signal of RazakSAT's $\mathrm{X}$-band satellite link is presented. The radar data employed was attained from the Malaysian Meteorological Department's (MMD) terminal Doppler weather radar installed strategically in the vicinity of Kuala Lumpur International Airport (KLIA). The X-band (8 GHz) satellite-Earth signals of Malaysian RazatSat's collected at the National Space Agency (NSA) space center have been analyzed and studied. The vertical polarization S-band radar reflectivity information was used to calculate the likely rain attenuation along the RazakSAT satellite propagation paths. This was carried out by first converting the radar reflectivity values into rainfall rate using the established Z-R relations of Marshall-Palmer equation and, afterwards, by evaluating the slant path attenuation through the assimilation of the specific rain attenuation derived at the rainfall rate.
\end{abstract}

Index Terms-Rain attenuation, radar, tropical region, $\mathrm{X}$-band, slant path.

\section{INTRODUCTION}

RazakSAT is the second Malaysian remote sensing satellite launched into the Near Equatorial Orbit ( $\mathrm{NEqO})$ on 14 July 2009. The received power signals of its X-band downlink were monitored and recorded by the telemetry, tracking and command (TT and C) center of Malaysian National Space Agency. Acquired signals during rain were compared to those of clear sky condition in the course of quantifying the attenuation measurements. In a tropical country like Malaysia, extreme rainfall is a frequent phenomenon throughout the year. The detailed recognition of the rain fade at the desired frequency of operation is critical for the design of a reliable terrestrial and/or Earth space communication link. It is of utmost importance to be able to accurately anticipate the possible impairment encountered on a given link. A number of results and models have been proposed and are already made available, providing a thorough description of the main propagation impairments such as rain attenuation, gaseous absorption, cloud attenuation, scintillation, depolarization and atmospheric noise [1]. These effects highlighted are particularly related within the tropospheric region. Among the most effective

Manuscript received March 10, 2013; revised April 17, 2013.

K. Badron, A. F. Ismail, A. Z. Jusoh, and N. H. M. Sobli are with the International Islamic University Malaysia, P.O. Box 10, 50728 Kuala Lumpur, Malaysia (e-mail:khairayu@iium.edu.my, af_ismail@iium.edu.my, azamani@iium.edu.my, hudaa@iium.edu.my).

M. Ismail is with the Malaysian National Space Agency. (e-mail:maszlan@angkasa.gov.my).

W. Hashim is with the Malaysian Institute of Microelectronic Systems (MIMOS Berhad), Kuala Lumpur, 57000 Malaysia (e-mail: wahidah.hashim@mimos.my). techniques that can be used to measure rain attenuation is by conducting experiments, where the received signal strength of a satellite beacon is monitored concurrently with radar observation [2]. In this aspect, any available radar reflectivity data becomes an attractive option for the study of rain attenuation estimation and prediction. The radar reflectivity data can be of huge advantage in predicting rain attenuation due to its wide volume area coverage. The renowned Z-R relation by Marshall and Palmer [3] that relates the value of the measured reflectivity to the value of the rainfall rate is according to;

$$
Z=a R^{b}
$$

where the radar reflectivity factor, $Z\left(\mathrm{~mm}^{-6} \mathrm{~mm}^{3}\right)$ and the rainfall rate, $R(\mathrm{~mm} / \mathrm{hr})$, are dependent on the rain drop size distribution (DSD) [3]-[6]. Marshall and Palmer published the $Z-R$ relation using the exponential DSD with a set of general parameters of $a=200$ and $b=1$.6. Since radar reflectivity and rain rate are functions of the DSD, and the drop size distribution depends on the rainfall process and varies geographically, there can be drastic differences in the parameters of the $Z-R$ relation at different geographical locations [7]. One of the concerns would involve convective rain events that are widespread over the tropical regions. These convective events experienced in the tropics are expected to have a different $Z-R$ relation with respect to the stratiform rain events that typically experienced in the temperate regions and the sub-tropical regions. For the tropics, a selection number of $a$ and $b$ parameters have been proposed by previous researchers [8]-[10]. In the study, radar data corresponding to period of RazakSAT operational campaigns were procured. The estimated attenuation evaluated from the radar reflectivity using data obtained from the Malaysian Meteorological Department (MMD) located at Sepang, Selangor was weighted against the measured satellite slant path rain attenuation. The displacement between the two locations is approximately $19 \mathrm{~km}$. An introductory analysis pertaining to the rain attenuation assessment on the X-band satellite links is also included in this paper. One of the critical aims of the study is to ensure as well as validating the reliability of the attenuation due to rain estimated / extrapolated from the Z-R relation models. In achieving such objective, the RazakSAT satellite link information were compiled and processed where the measured attenuation data were utilized to corroborate the results obtained from the radar modeled data.

\section{DESCRIPTION OF SyStem AND DATA}

\section{A. Radar System}

The investigation of rain attenuation made use of single 
polarization S-band terminal Doppler weather radar data with an operating frequency of $2.75 \mathrm{GHz}$. It is located about $10 \mathrm{~km}$ north from the Kuala Lumpur International Airport. The radar system is programmed to operate in two scanning modes. Each mode includes sweeps of the surrounding area at a predetermined elevation angles. Each elevation contains 360 rays of data corresponding to 360 azimuth angles with no interlaced beams. The radar antenna rotates at the speed of 2 revolution per minute (RPM) with pulse repetition frequency (PRF) equals to $300 \mathrm{~Hz}$ for scanning elevation angles of less than $5^{\circ}$. The radar will be rotating at faster speed of 4 revolution per minute (RPM) with PRF equals to $1000 \mathrm{~Hz}$ for angles of elevation between $5^{\circ}$ to $40^{\circ}$.

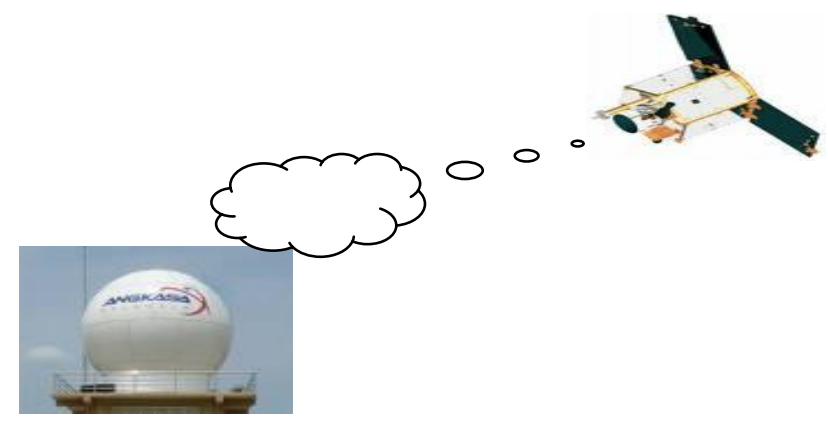

Fig. 1. Overview of RazakSat system configuration and the ground station located at banting, Selangor.

TABLE I: RAZAKSAT SPECIFICATIONS

\begin{tabular}{cc}
\hline Item & $\begin{array}{c}\text { Specifications } \\
\text { Orbit }\end{array}$ \\
& $\begin{array}{c}\text { Near Equatorial Low Earth Orbit } \\
(\mathrm{NeqO})\end{array}$ \\
\hline Altitude & $685 \mathrm{~km}$ \\
\hline Inclination & $9^{\circ}$ \\
\hline Mass & $187.6 \mathrm{~kg}$ \\
\hline Envelope & f1200mm ' $\mathrm{H}^{\prime} 1200 \mathrm{~mm}$ \\
\hline Attitude Control Accuracy & $0.2^{\circ}$ \\
\hline Power & $>300 \mathrm{~W}$ \\
\hline Payload & Medium-sized Aperture Camera \\
\hline Mass Storage Capacity & 32 Gbits \\
\hline Data Down Link & bps (X-Band)
\end{tabular}

\section{B. RazakSAT Satellite System}

The X-band ( $8 \mathrm{GHz}$ ) transmission signals from RazakSAT were received, monitored, and tracked by the Hexapod antenna. The signals were amplified and down-converted into Intermediate Frequency (IF) before ingested to the High-rate Data Receiver (HDR) for demodulation of QPSK signal and bit synchronization. RazakSAT can be considered as a small Low Earth Observation (LEO) weighing only at about $200 \mathrm{~kg}$. The satellite orbits the Earth in a unique positioning identified as Near Equatorial Orbit (NEqO), at nominal altitude of $685 \mathrm{~km}$ and 9 degrees inclination. It carries a Medium-sized Aperture Camera (MAC) which is the electro-optical payload of a pushbroom camera type with 5 linear detectors (1 panchromatic, 4 multi-spectral). RazakSAT is operated and controlled from its ground segment located in Sungai Lang, Banting, Selangor, Malaysia. The ground segment i.e. Malaysian Space Center consists of a Mission Control Station (MCS) and an Image Receiving and Processing Station (IRPS). The RazakSAT mission plan, command generation and telemetry receiving, archiving and analysis was executed accordingly at the MCS by a dedicated team of satellite engineers. Fig. 1 offers the impression of the RazakSAT and the MCS system configuration. Table I outlines some the satellite configurations [11].

\section{REsults AND Discussion}

Signal received from RazakSAT are available almost 14 times daily for duration of about 20 minutes each event. The signals received each time the satellite passes the ground station during clear sky and rain downpour were identified, measured and compared in the course of action of calculating the rain attenuation. Preliminary result involving the event recorded on 24/8/2009 is shown in Fig. 2, Fig. 3, Fig. 4 and Fig. 5, where clear sky condition (at 09:4009:55) and attenuated power received signal (at 04:24-04:38) respectively. Fig. 2 and 4 shows the rain events plotted versus the received power signal whilst Fig. 3 and 5 demonstrate the elevation angle of the orbiting satellite versus power received signal during clear sky and rain events respectively. The X-band signals at $40^{\circ}, 20^{\circ}$ and $15^{\circ}$ elevation angles were measured and the variations are listed in Table II.

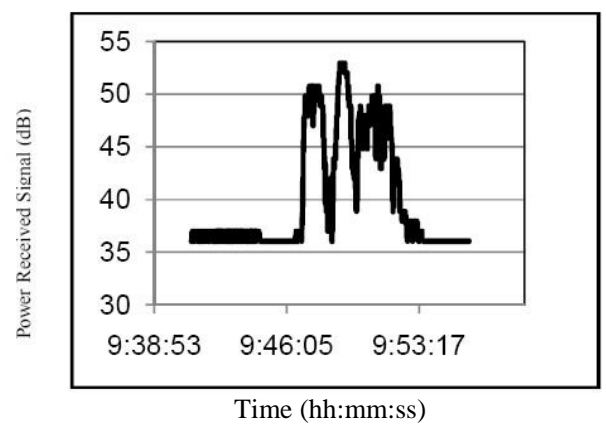

Fig. 2. RazakSAT's power received signal time event during clear sky condition.

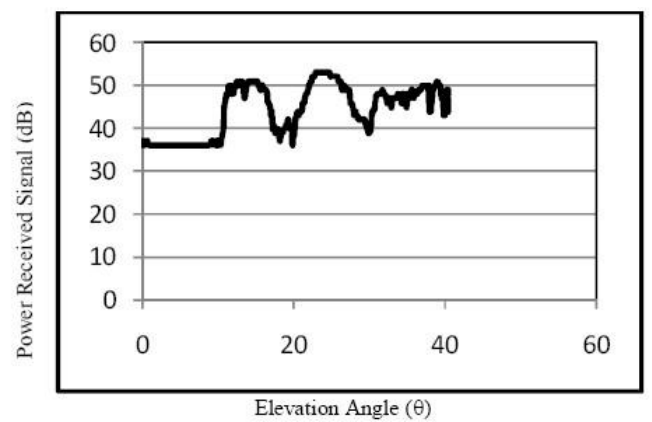

Fig. 3. RazakSAT's power received signal plotted versus elevation angle of the satellite during clear sky condition.

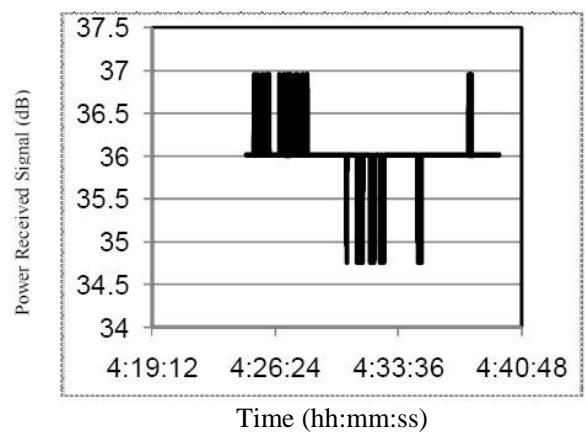

Fig. 4. RazakSAT's power received signal time event during rain downpour condition. 


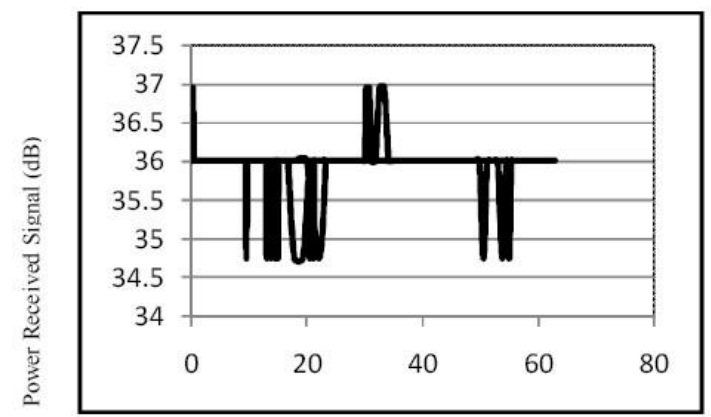

Fig. 5. RazakSAT's power received signal plotted versus elevation angle of the satellite during downpour condition.

TABLE I: RAZAKSAT DATA COMPARISON DURING CLEAR SKY AND RAIN

\begin{tabular}{cccc}
\hline \multicolumn{4}{c}{ EVENTS } \\
$\begin{array}{c}\text { RazakSat } \\
\text { angle }\end{array}$ & $\begin{array}{c}\text { Power } \\
\text { Received } \\
\text { Signal } \\
\text { during clear } \\
\text { sky } \\
\text { (dB) }\end{array}$ & $\begin{array}{c}\text { Power } \\
\text { Received } \\
\text { During } \\
\text { Rain (dB) }\end{array}$ & $\begin{array}{c}\text { Attenuation } \\
(\mathbf{d B})\end{array}$ \\
\hline $40^{\circ}$ & 43 & 36 & 7 \\
\hline $20^{\circ}$ & 44 & 38 & 5 \\
\hline $15^{\circ}$ & 38 & 36 & 2 \\
\hline
\end{tabular}

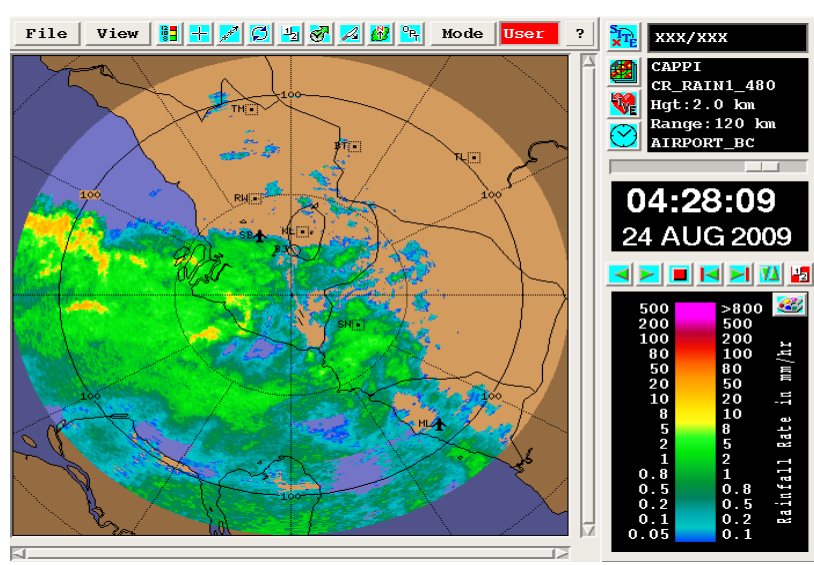

Fig. 6. Rain events confirmed using IRIS software.

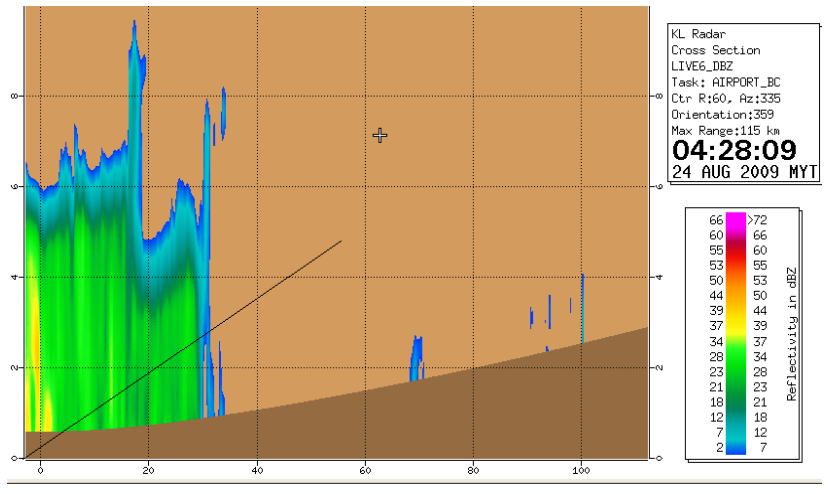

Fig. 7. RHI scans from ground station towards RazakSAT path at $40^{\circ}$ elevation angle.

The corresponding MMD S-band radar data of the said date and times were retrieved in order to authenticate that the RazakSAT slant path satellite-Earth link was indeed attenuated by heavy downpour. The radar image confirms the existence of rain events where Fig. 6 shows the Plan Position Indicator (PPI) snapshot at the stipulated time from radar data generated using IRIS software where convective rains existed as expected. Concurrently, Fig. 7 portrays the display of
Range Height Indicator (RHI) scan for the rain event on $24^{\text {th }}$ August 2009 at the time 04:28:09. The vertical axis indicates the height above ground from the ground station site up to 10 $\mathrm{km}$ with clear indication of the rain height. The horizontal axis on the other hand shows the range distance from the station. In the approach of identifying the probable estimation using the radar information, a solid line was sketched emulating the slant path range distance from ground station to satellite site at Banting, Selangor at $40^{\circ}$ elevation angle. The color bar in both figures indicates the reflectivity (dBZ) that was detected by the radar.

The total slant path attenuation was then calculated through the numerically summation of;

$$
\sum_{i=0}^{n} k R_{i}^{\alpha} . \Delta L i
$$

In (2), $R_{i}$ is the rainfall rate value and $\Delta L_{i}$ is the path length at each Cartesian $i^{\text {th }}$ pixel along the slant path between the Earth station and the satellite. Therefore, from the RHI scan, the attenuation can be estimated using radar reflectivity, $d B Z$ values based on each Cartesian grid or what is typically identified as bins. Converting $\mathrm{dBZ}$ to $Z$ was achieved using the equation;

$$
d B Z=10 \log Z
$$

After calculating each bins along the slant path at different elevation angles of interest $\left(40^{\circ}, 20^{\circ}\right.$ and $\left.15^{\circ}\right), Z=2.5 \times 10^{30}$ $\mathrm{mm}^{6} \mathrm{~mm}^{-3}$ was identified. Subsequently, the $Z-R$ relation relates the value of the measured reflectivity to the value of the rain rate according to the general formula given in (1) by Marshall and Palmer. According to Marshall-Palmer, the radar reflectivity factor and the rain rate are both dependent on the rain drop size distribution (DSD) [12]-[14]. Marshall and Palmer is a well-known $Z-R$ relation that was somewhat optimized for stratiform type of precipitation. With reflectivity, $Z$ is equal to $10^{30.4} \mathrm{~mm}^{6} \mathrm{~mm}^{-3}$, whilst $Z=200 R^{1.6}$ and hence $R=3.6 \times 10^{17} \mathrm{~mm} / \mathrm{hr}$. From rainfall rate, the specific attenuation can be calculated at the specified X-band frequency using ITU-R Rec. P.838-3 [15];

$$
\gamma=k R^{\alpha}
$$

The coefficients of specific attenuation, $k$ and $\alpha$, can be obtained from the ITU-R Rec. P.838-3and are dependent on the link elevation angle, the radiowave frequency and polarization as shown;

$$
k=\left[k_{H}+K_{V}+\left(k_{H}-k_{V}\right) \cos ^{2} \theta \cos 2 \tau\right] / 2
$$

$\alpha=\left[k_{H} \alpha_{H}+k_{V} \alpha_{V}+\left(k_{H} \alpha_{H}-k_{V} \alpha_{V}\right) \cos ^{2} \theta \cos 2 \tau\right] / 2 k$

Table III shows the value suggested by ITU-R Rec. P.838-3.

TABLE III: ITU-R REC. P.838-3 SUGGESTED VALUE FOR $K$ AND $\alpha$.

\begin{tabular}{cl}
\hline Frequency $(\mathbf{G H z})$ & $\mathbf{8}$ \\
\hline $\mathrm{kH}$ & 0.004115 \\
\hline$\alpha \mathrm{H}$ & 1.3905 \\
\hline $\mathrm{kV}$ & 0.003450 \\
\hline$\alpha \mathrm{V}$ & 1.3797 \\
\hline
\end{tabular}

The corresponding values at $8 \mathrm{GHz}$ frequency for $k$ and $\alpha$ 
are 0.00369399 and 0.0126 respectively. Substituting $k$ and $\alpha$ values to the equation (4) the specific attenuation, $\gamma$ can be obtained equating to value of $0.012 \mathrm{~dB} / \mathrm{km}$. Several angles of the satellite slant path length were assessed where each elevation angle offers different attenuation levels as tabulated in Table IV.

TABLE IV: ESTIMATED ATTENUATION LEVELS FROM RADAR REFLECTIVITY AT DIFFERENT ELEVATION ANGLE.

\begin{tabular}{ccccc}
\hline $\begin{array}{c}\text { Elev } \\
\text { angle }\end{array}$ & $\begin{array}{c}\text { Path } \\
\text { length } \\
(\mathbf{k m})\end{array}$ & $\begin{array}{c}\text { Radar } \\
\text { estimated } \\
\text { values (dB) }\end{array}$ & $\begin{array}{c}\text { Satellite } \\
\text { Measurements } \\
(\mathbf{d B})\end{array}$ & Variation \\
\hline $40^{\circ}$ & 42 & 5 & 7 & 2 \\
\hline $20^{\circ}$ & 34 & 4 & 5 & 1 \\
\hline $15^{\circ}$ & 33 & 3 & 2 & 1 \\
\hline
\end{tabular}

\section{CONCLUSION}

Based on the selected rain event, it can be concluded that the values calculated from the radar reflectivity estimation are found to be lower when compared to the actual satellite measurements. These indicate and suggest that an improvement in the formula should be thoroughly researched The next subsequent research undertaking will involve attempts of devising a formula that can accurately predict the attenuation using the radar reflectivity information. At this particular instance, it is observed that lower elevation involves lower attenuation with minimal variation than higher elevation angle where longer path length is affected by rain. The satellite transmission link performance is strongly dependent on the path length affected by rain as well as precipitation characteristics along the slant path, where both affect the system performance significantly. The research will evidently attempt to configure a new model to derive rain attenuation prediction using radar information in tropical region.

\section{ACKNOWLEDGMENT}

Special gratitude goes to the Malaysian National Space Agency and Malaysian Meteorological Department for their aide in technical support and furnishing such invaluable data. The authors also acknowledge the Research Management Centre of the International Islamic University Malaysia (IIUM) for the financial support. The reported research findings are part of the deliverables for the research funded under IIUM's Research University Initiatives. The work is currently being supported in part by the International Islamic University Malaysia under EdwB2011 and RAGS grants, collaboration research with Malaysian National Space Agency.

\section{REFERENCES}

[1] R. K. Crane, "Prediction of attenuation by rain," IEEE Trans. Commun., vol. Com-28, no. 9, pp. 1717-1733, Sep. 1980.

[2] A. Hornbostel and A. Schroth, "Comparison of radiometer, radar and rain gauge attenuation predictions with Olympus beacon measurements," in Proc. 9th Int. Conf. Antennas Propag. (Conf.Publ.No.407), Apr. 4-7, 1995.

[3] J. S. Marshall and W. K. Palmer, "The distribution of raindrops with size," J. Atmospheric Sci., vol. 5, no. 4, pp. 165-166, 1948.

[4] L. J. Battan, Radar observations of the atmosphere, Chicago: Univ. Chicago Press, 1973, vol. 323.

[5] C. W. Ulbrich, "Natural variation in the analytical form of the raindrop size distribution," J. Appl.Meteor, vol. 22, no. 10, pp. 1764-1775, 1983.

[6] J. X. Yeo, Y. H. Lee, L. S Kumar, and J. T. Ong, "Comparison of S-Band Radar Attenuation Prediction With Beacon Measurements," Antennas and Propagation, IEEE Transactions on, vol. 60, no.10, pp.4892-4900, Oct. 2012

[7] G. Villarini and W. F. Krajewski, "Review of the different sources of uncertainty in single polarization radar-based estimates of rainfall," Surveys Geophys., vol. 31, pp. 107-129, 2009.

[8] L. S. Kumar, Y. H. Lee, J. X. Yeo, and J. T. Ong, "Tropical rain classification and estimation of rain from Z-R (reflectivity-rain rate) relationships," Progr. Electromagn. Res. B, vol. 32, pp. 107-127, 2011.

[9] C. L. Wilson and J. Tan, "The characteristics of rainfall and melting layer in Singapore: Experimental results from radar and ground instruments," in Proc. 11th Int. Conf. Antennas Propag., Apr. 2001, pp 852-856.

[10] S. Das, S. Talukdar, A. Bhattacharya, A. Adhikari, and A. Maitra, "Vertical profile of Z-R relationship and its seasonal variation at a tropical location," in Proc. Applied Electromagnetics Conference (AEMC), 2011 IEEE , vol. 1, no. 4, pp. 18-22, Dec. 2011.

[11] Astronautic Technology Sdn Bhd - Wikipedia, the free encyclopedia. [Online]. Available: http://www.atsb.my

[12] M. Montopoli, G. Vulpiani, M. N. Anagnostou, E. N. Anagnostou, and F. S. Marzano, "Processing disdrometer raindrop spectra time series from various climatological regions using estimation and autoregressive methods," in Proc. IEEE International, Geoscience and Remote Sensing Symposium, vol. 2268, no. 2271, pp. 23-28, July 2007.

[13] Y. Y. Zheng and X. Wang, "A study of drop-size distribution in precipitation cloud from wind profile radar," Education Technology and Training, 2008 and 2008 International Workshop on Geoscience and Remote Sensing. ETT and GRS 2008. International Workshop on, vol. 1, no. 571-574, pp. 21-22, Dec. 2008.

[14] D. Tokay and A. Short, "Evidence from tropical raindrop spectra of the origin of rain from stratiform versus convective clouds," J. Appl. Meteor., vol. 35, no. 3, pp. 355-371, 1996.

[15] ITU-R: Specific Attenuation Model for Rain for Use in Prediction Methods, Rec. ITU-R P. 838-3 Geneva, 2005

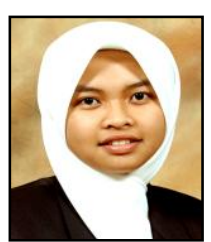

K. Badron obtained her BEng and MSc from International Islamic University Malaysia (IIUM) in 2007 and 2011 respectively. She is currently one of the faculty members of Faculty of Engineering, IIUM and recently commenced her $\mathrm{PhD}$ studies in Radar and Radiometry research, quantifying propagation effects on microwave and millimeter links. Khairayu is a member of IEEE and has published and co-authored more than ten papers in International Journals as well as Conferences on subjects relating to rain attenuation in the tropical regions.

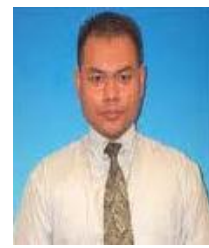

A. F. Ismail is currently serving as a lecturer at the Department of Electrical and Computer Engineering, Faculty of Engineering, International Islamic University Malaysia. He completed his bachelor degree studies in Electrical Engineering at Gannon University, Pennsylvania, USA with Cum Laude Latin honors. He holds MSc from University of Essex, $\mathrm{UK}$ and $\mathrm{PhD}$ from University of Bath, UK. His research interests include millimeter and microwave propagation studies, development of active and passive target tracking algorithms and Cognitive Radio applications. He is a registered Professional Engineer with Board of Engineering Malaysia and also a Senior Member of the IEEE.

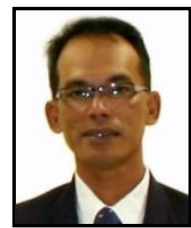

M. Ismail is the Malaysian National Space Agency director. He directs the satellite ground operation as well as the spacecraft testing facilities. He was the principal engineer for Malaysian Remote Sensing Satellites -RazakSAT and TiungSAT. Maszlan received his BEng and MSc from the National University of Malaysia specializing in wireless and satellite communication. He is one of the committee members of IEEE Malaysian chapter and Asia-Pacific Regional Space Agency Forum.

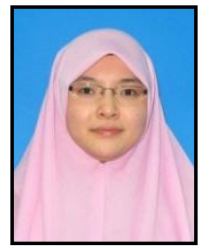

modeling
N. H. M. Sobli is a fellow lecturer at the Dept of Electrical and Computer Engineering, Faculty of Engineering, International Islamic University Malaysia. She received BEng and MSc from International Islamic University Malaysia specializing in communications engineering. She is currently pursuing her Ph.D candidacy. Her research interests are wireless communication, radar radiometry and rainfall rate 


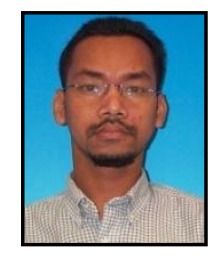

A. Z. Jusoh obtained his B.Eng in Electrical Eng. from Hanyang University, Korea in 1999 and completed his M.Sc in Electrical Eng. at Lougborough University, UK in 2004. He received $\mathrm{PhD}$ in Electronics from the University of Western Australia University, Perth, Australia. $\mathrm{He}$ is an assistant professor at faculty of Engineering, International Islamic University Malaysia. His research interests are in the area of novel modulation techniques as well as advance error detection design. He is a member of IEEE and member of IEM.

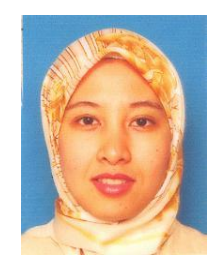

W. Hashim received his bachelor degree in Information Technology, Business Management and Language from University of York, UK in 1999. She then pursued her MSc in Multimedia Technology at University of Bath $\mathrm{UK}$ in 2001. She completed her $\mathrm{PhD}$ studies from King's College London, UK in 2008 in the field of Telecommunication Engineering. She is currently a staff researcher at the Wireless Communication Cluster, MIMOS Berhad with focus in cognitive radio, WLAN, OFDM, space-time coding, MIMO systems and wireless system. 